\title{
Solutions to Negative Emotions
}

\author{
Ronald H. Humphrey \\ Lancaster University Management School \\ Lancaster University \\ Lancaster, United Kingdom \\ Neal M. Ashkanasy \\ UQ Business School \\ The University of Queensland \\ Brisbane, QLD, Australia \\ Ashlea C. Troth \\ Griffith Business School \\ Griffith University \\ Brisbane, QLD, Australia
}

Author accepted manuscript. Please cite as:

Humphrey, R.H., Ashkanasy, N.M. and Troth, A.C. (2022), "Solutions to Negative Emotions", Humphrey, R.H., Ashkanasy, N.M. and Troth, A.C. (Ed.) Emotions and Negativity (Research on Emotion in Organizations, Vol. 17), Emerald Publishing Limited, Bingley, pp. 277-290. https://doi.org/10.1108/S1746-979120210000017019

Chapter submitted for inclusion in Humphrey, R. H., Ashkanasy, N. M., \& Troth, A. C. (Eds.) (forthcoming). Research on emotion in organizations, Volume 17: Emotions and negativity. Bingley, UK: Emerald Group Publishing. 


\title{
Solutions to Negative Emotions
}

\begin{abstract}
Purpose: In this summative chapter, the volume editors discuss some of the "antidotes" to negative emotions that the authors in this volume have set out.
\end{abstract}

Design: The summary is arranged in five sections: (1) Negative emotions as learning opportunities; (2) attributions and cognitive reframing; (3) importance of emotional intelligence; (4) leader empathy and organizational support; and (5) benefits of solving employee negative emotions.

Findings: $\quad$ Despite the pervasiveness of negative emotions and experiences in organizations, they can lead to positive outcomes if handled appropriately.

Research The chapters focus on a wide variety of important but under-researched Implications: topics in emotions and affect; and contain many original solutions to dealing with such emotions that may ultimately prove beneficial to organizations.

Practical Organizations that are good at helping their employees cope with negative Implications: emotions have a competitive advantage in improving their employees' job performance and organizational commitment.

Social The negative emotions examined in the volume chapters have an impact on Implications: employee well-being. Thus, coping with these emotions is crucial to society.

Originality/ The chapters in this volume provide a variety of original solutions to what value: $\quad$ some might see as an "epidemic"" of negativity in organizations. 


\section{Solutions to Negative Emotions}

The chapters in this volume explore a wide variety of intense negative emotional experiences at work, including failure, job insecurity, social rejection and abuse. The authors of these chapters have also proposed insightful solutions to these negative events and emotions. In this chapter, we go over their solutions while also proposing a few suggestions of our own. We hope academic researchers will be stimulated to do new research on these proposed solutions. In addition, we believe that practicing managers and employees might find these remedies useful in their own working lives. We have arranged these solutions into five categories:

1. Failure and other negative experiences as learning opportunities: The positive side of negative emotions.

2. The crucial role of attributions and cognitive reframing.

3. The importance of emotional intelligence, emotional management, and psychological resilience.

4. The role of leader empathy and organizational support in helping employees cope.

5. The benefits to organizations of solving employee negative emotions: Better performance and organizational commitment.

As readers can see from these categories, we begin and end with a positive perspective. Negative emotions and experiences can sometimes have positive outcomes for both individuals and organizations, and organizations that are good at helping their employees cope with negative emotions have a competitive advantage in improving their employees' job performance and organizational commitment. 


\section{Failure and Other Negative Experiences as Learning Opportunities: The Positive Side of Negative Emotions}

The authors of two of the chapters in this volume (Chapters 1 and 11) emphasize that negative emotions and experiences may ultimately have some positive long-term benefits. The first chapter on failure, by Smollan and Singh, considerably expands on this theme. As the authors rightly observe, failure can be a learning experience. Thomas Edison is reputed to have famously stated on his early efforts to create a lightbulb, "I have not failed. I've just found 10,000 ways that won't work." ${ }^{1}$ In many areas of life and work, failure is part of the learning process. Indeed, as Edison would have known so clearly, failure is an essential part of innovation and creativity, and Smollan and Singh were right to emphasize how failure can lead to new ideas and inventions. Moreover, as they point out, failure can lead to renewed commitment and extra effort; or to the exploration of other more fruitful avenues. Perceptively, Smollan and Singh also recognize that positive emotions, such as pride and hope, in combination with the experience of failure can lead to rosy outcomes. These positive emotions and personality traits can steer actors to respond to failure with renewed effort and creativity instead of giving in to despair and shame. As Edison further observed, "Many of life's failures are people who did not realize how close they were to success when they gave up." 2

Likewise, in Chapter 11, Svetieva and Lopes also argue that we should not take for granted that positive emotions invariably produce the best outcomes. In a provocative study, they explore the effects of supervisors' emotional displays and feedback specificity on subordinates' perceptions of the leader and on subordinates' motivation levels. Their study highlights that emotional displays are an art form and must be managed with skill and sophistication. This

\footnotetext{
${ }^{1}$ As quoted by Elkhorne (1967, p. 52)

${ }^{2}$ As quoted by Henderson (2007, p. 22).
} 
important conclusion echoes earlier findings by Newcombe and Ashkanasy (2002) that a leader who attempts to provide positive feedback while at the same time displaying negative expression is likely to be seen as untrustworthy by subordinates.

The work on leader emotional labor (see Ashkanasy \& Humphrey, 2011; Humphrey, 2012; Humphrey et al., 2008) also argues that leaders need to use judgment and discretion when deciding on the most appropriate emotional displays to show to employees. In general, although leaders who create a positive workplace culture and who express positive emotions to their employees do best overall (Burch et al., 2013; Humphrey, 2008), there are some situations where displays of negative emotions are appropriate and even necessary (Humphrey et al., 2008; Newcombe \& Ashkanasy 2002).

In fact, human beings evolved all their emotions, even ostensibly negative emotions like anger and fear, because they helped us survive (Ashkanasy et al., 2017). Anger may be useful, although too often it is used inappropriately. As Aristotle stated, anger is what the just man feels at injustice, yet "Anybody can become angry - that is easy, but to be angry with the right person and to the right degree and at the right time and for the right purpose, and in the right way - that is not within everybody's power and is not easy."3 Thus, while it might be appropriate for managers to display anger to employees who are willfully doing wrong, displaying this anger to the right degree and in the right way requires considerable judgment and emotion management skills. When employees are purposely working slowly or otherwise misbehaving, displays of impatience, irritation, and even anger might produce improvements in performance. Nonetheless, a wise manager would also seek to uncover and address any factors, such as poor working

\footnotetext{
${ }^{3}$ As quoted by Leonard, Miles, \& Van der Kar (1942, p. 203)
} 
conditions, unfair treatment, etc. that might be motivating employees to commit counterproductive work behaviors.

\section{The Crucial Role of Attributions and Cognitive Reframing}

Many of the authors in this volume convincingly argue that how people respond to negative events plays a large role in how they are affected by the events. In particular, people's attributions about the causes of the events, and their ability to use cognitive reappraisal, play a large role in how well they can cope with the negative incidents. Smollan and Singh argue in Chapter 1 that people with higher emotional intelligence can avoid unproductive rumination about failures and use various cognitive reappraisal techniques to help them interpret failure in more useful ways. By using cognitive reappraisal, people may reframe failure as a learning opportunity, not as a final defeat.

This perspective on reframing failure as a learning opportunity is consistent with the research on learning orientation (Dweck \& Leggett, 1988). According to this model, people with a learning goal orientation see mistakes as a natural part of the learning process, and as a result, they maintain a positive attitude and are also willing to try risky opportunities and engage in learning new skills. In contrast, people with a performance goal orientation see performance in terms of the end goal, as opposed to learning and development.

There are two types of performance goal orientation, moreover: (1) prove goal orientation and (2) avoid goal orientation. People with a prove goal orientation prefer to stick with tasks that they can already perform well, thus showing off their skills in areas they are already competent in. This hinders willingness to try new tasks and the learning of new skills. People with an avoid goal orientation aim to avoid failure and embarrassment, thus they are even more averse to learning through failure. In a demonstration of this, De Pater and her colleagues 
(2009) gave participants in an assessment center the opportunity to perform either complex tasks or simple repetitive tasks. Those with an avoid orientation were more likely to perform the simple tasks. This had considerable career implications because the study found that performing complex tasks increased perceptions of competency for career advancement.

Leaders can also increase a person's willingness to adopt a learning goal orientation. For example, Dragoni (2005) found that the instructions that leaders give to employees influences whether they see a task as a learning opportunity. Leaders may also increase their followers' learning goal orientations and response to feedback by creating positive leader-member exchange relationship with their followers (Bezuijen et al., 2010).

In Chapter 2, Russell and Victoria outline the coping strategies in use by environmental change agents, and also examine reappraisals methods. In particular, these authors examined the research on three styles of coping: (1) meaning focused, (2) problem focused, and (3) emotion focused. Meaning focused coping is a type of cognitive reappraisal method and, according to some research (e.g., see Folkman, 2008; Folkman \& Moskowitz, 2007; Guo et al., 2013) is the most effective of the three coping mechanisms. Meaning focused coping enables us to interpret events in more productive emotional ways, in essence, to rewrite our own stories in a way that promotes self-esteem, motivation, and a sense of purpose. Russell and Victoria also highlight the importance of emotional resilience, a concept similar to the psychological resilience espoused by Luthans and his colleagues (2006), which we will go over in the next section.

Moura and her co-authors detail in Chapter 8 their findings about the experience of and response to anger, and they argue for the crucial role that attributions and cognitive reappraisals play in coping strategies. These authors maintain that targets of anger have better health outcomes when they attribute sender's anger to external events (an external attribution) rather 
than to the sender (an internal attribution). They further tout cognitive reappraisal as an effective strategy since prior research (e.g., see Gross \& John, 2003) has related it to positive health outcomes. Like Gross and John, Moura and her associates also found that targets of anger who used expression as a strategy had fewer negative health outcomes and higher self-esteem. In contrast, they found that those who used the suppression of emotions to cope with being the target of anger had worse health outcomes.

Wei and her colleagues in Chapter 10, addressing the paradoxical situation in which supervisors are compassionate but unethical, focus on a related process: sensemaking. These authors argue that employees engage in sensemaking activities to understand the apparent discrepancies in their supervisors' behaviors. Followers' interpretation of both the situation and their managers' behaviors influence followers' emotional responses and the extent to which they form a shared moral identity with their supervisors. Moreover, Wei et al. argue this process can ultimately decide whether followers will engage in unethical behavior themselves at the behest of their supervisors. Most of the major ethical scandals that have rocked the business and political world in the last few decades have involved large numbers of willing and compliant subordinates. Thus, the theories the authors of this chapter lay out should have widespread applicability that, in turn should help followers to recognize when they are falling into these ethical traps (and thus may form a partial solution to this complex problem).

\section{The Importance of Emotional Intelligence, Emotion Management, and Psychological}

\section{Resilience}

As Ashkanasy and Humphrey (2011) point out, the ability to manage emotions plays an important role in almost all the proposed solutions to negative emotions. This theme is taken up in Chapter 6, where Fischbach and Schneider outline how emotional labor (as a form of 
emotional regulation - see Troth et al., 2018) can be leveraged to enable organizations to deal with setbacks and to catalyze successful outcomes. Similarly, the authors of Chapter 7 (Langerud and his associates) note that emotional regulation motives can play a key role in turning negativity into positive outcomes. Their chapter addresses an important and frequent occurrence, unmet entitlement needs.

Not surprisingly, many of the chapter authors (e.g., Smollan and Singh in Chapter 1, Russell and Victoria in Chapter 2) mention the important role that emotional intelligence plays in helping people cope with negative emotions. Ashkanasy and Daus (2005) classified the research on emotional intelligence into three "streams:" (1) ability measures, (2) self-reports, and (3) mixed competencies models. The MSCEIT V2.0 (Mayer, 2002) is the most well-known Stream 1 ability measure of emotional intelligence. The ability approach emphases the "intelligence" aspects of emotional intelligence, and measures emotional intelligence using objective right and wrong questions analogous to the way cognitive ability is measured. In contrast, both the Streams 2 and 3 measures use self-reports (or sometimes peer/supervisor/other ratings). Thus, they measure emotional intelligence the same way as most measures of personality. Indeed, some researchers in these two camps regard emotional intelligence as a type of personality trait (Petrides et al., 2007). For example, "Trait EI" has been defined as “a constellation of emotion-related self-perceptions and dispositions located at the lower levels of personality hierarchies" (Vernon et al., 2008, p. 635, based on Petrides et al., 2007).

The main differences between Stream 2 and 3 measures are that Stream 3 measures incorporate a wider variety of emotion-related abilities, such as conflict management, and many mixed competencies models also include learned skills in addition to personality traits (Bar-On, 1997; Boyatzis, 2011). Although the three streams differ somewhat in their conceptualizations of 
emotional intelligence, all include the ability to perceive and manage emotions, both within oneself and about others.

This idea is reinforced in a meta-analysis by Andrei et al. (2016), who investigated whether the Trait Emotional Intelligence Questionnaire (TEIQue) has incremental validity when predicting coping ability and other measures of well-being. Of relevance to our discussion is their finding that the TEIQue shows incremental validity when predicting coping (see Petrides et al., 2007) and coping strategies, rumination, and life satisfaction.

Meta-analyses further confirm the importance of a more comprehensive set of emotional intelligence measures to mental and physical health outcomes. The first emotional intelligence to health meta-analysis, by Schutte et al. (2007), found that "emotional intelligence had a weighted average association of $r=.29$ with mental health, $r=.31$ with psychosomatic health, and $r=.22$ with physical health" (p. 921). The second meta-analysis, by Martins et al. (2010), confirmed the earlier results. In a third meta-analysis, Sarrionandia and Mikolajczak (2020) sought to understand why trait emotional intelligence is positively related to both mental and physical health. These authors found that emotional intelligence positively links to healthy behaviors, including social support, a healthy diet, physical activity, and adequate sleep, and negatively related to unhealthy behaviors, such as risky sexual behavior, reckless driving, and substance abuse.

Relatedly, Troth et al. (2021), in a chapter on emotions and wellbeing at work, discuss evidence regarding how an individual's emotional intelligence is positively associated with their level of workplace wellbeing and negatively with depression and burnout, and the role of gender (with stronger effects for women). These authors also present research suggesting emotional intelligence helps employees reduce their negative feelings, by increasing positive feelings, and/or by improving job performance. Moreover, Troth and her colleagues examine two negative 
workplace emotions (anger and fear) and consider that, while both these discrete emotions are closely tied to well-being, the nature of these ties are not necessarily deleterious, and will vary according to the stressor or affective event and appraisal to which they are attached; and how individuals manage those emotions. That is, both anger (e.g., remedying an injustice) and fear (e.g., motivate to seek help) have the capacity to lead to positive outcomes. Troth and her associates recommend that, to create productive and satisfied workers, organizations should incorporate EI in employee recruitment, training and development programs and consider "fit" in terms of individuals' emotional skills and emotional capabilities and the affective demands of the job.

Workplace conflict is a specific but common affective event that is associated with negative emotions and subsequent outcomes, typically harmful. However, Jordan and Troth (2002) show that individuals with higher levels of emotional intelligence are more likely, or are more able, to engage in collaborative conflict resolution, presumably due to their ability to manage and reframe negative emotion. Conversely, individuals with lower emotional skills were more likely to engage in conflict resolution strategies of forcefulness and avoidance. Jordan and Troth (2002) extended this to show a team's collective level of emotional intelligence positively influences team performance and drives individual conflict behavior during team performance. Thus, workplace conflict provides a good example of how phenomenon typically associated with negative emotions can lead to positive behavioral and performance outcomes with better emotional intelligence.

Job insecurity is another important situation that can provoke intense anxiety based on an all too often real and important threat to one's personal and financial well-being. In chapter 4, Jordan, Ashkanasy, and Lawrence demonstrate how job insecurity can create anxiety that in turn hinders effective decision-making. Importantly, these authors found that employees' who possess individual 
skills of being aware of emotions and managing emotions (two key emotional intelligence skills) were less likely to succumb to poor decision-making.

In another series of meta-analyses, authors have further demonstrated the incremental validity of emotional intelligence for a wide variety of the most important work-related outcomes. These meta-analyses have examined the relative importance of emotional intelligence, cognitive ability, and each of the Big Five personality traits. What has emerged from these studies is overwhelming support for the primacy of emotional intelligence as the best predictor across a wide range of important work-related outcomes (see Table 1 for a summary of these findings).

Table 1 about here

Two meta-analyses (Hodzic et al., 2018; Mattingly \& Kraiger, 2019) have also found consistent support for the effectiveness of training people in emotional intelligence abilities and competencies. Given the multitude of positive benefits that accrue from emotional intelligence, training people in emotional intelligence is likely to be the most important step that HR staff can do to mitigate negative emotions and to improve employee well-being and performance.

Our chapter authors also mention the role of emotional resiliency in coping with negative emotions (e.g., Russell \& Victoria in Chapter 2). Di Fabio and Saklofske (2018) examine the relative importance of emotional intelligence and personality to resiliency. Consistent with the meta-analyses data in Table 1, these authors found that emotional intelligence demonstrates incremental validity over personality measures when predicting both students and workers levels of resiliency. This is especially important because resiliency, by definition, refers to the ability to 
cope with negative emotions and other life stressors. Luthans (2002) defines resilience as the “positive psychological capacity to rebound, to 'bounce back' from adversity, uncertainty, conflict, failure, or even positive change, progress and increased responsibility" (p. 702).

Bartone (2006) uses a case analysis to describe the practical steps that a leader can take to build employee resilience. Humphrey (2013) summarized these steps under the following headings:

(a) Create meaning out of an ambiguous situation: employees need to feel that their work has a larger meaning and purpose.

(b) Participation and empowerment: allowing employees to participate in planning builds commitment.

(c) A controllable task: assign employees tasks that are within their abilities to complete and that have a definite beginning and end.

(d) Recognition: Give employees recognition and other awards to further build their resiliency.

Luthans et al. (2006) argue that human resources managers need to focus more on developing organizational support for employee resilience as well as developing employees' personal resiliency. Their recommendations offer some practical suggestions to HR professionals about how to increase resilience, which should in turn reduce problems due to negative emotions.

Training employees in mindfulness might also provide solutions to negative emotions. Studies have demonstrated that mindfulness-based therapy/exercises increase well-being, alleviate clinical and nonclinical problems (e.g., anxiety, stress, depression, negative feeling, pain, and burnout, etc.), and enhance work performance, job satisfaction, and social relations (Brown \& Ryan, 2003; Mesmer-Magnus et al., 2017; Schutte \& Malouff, 2011; Wright \& 
Schutte, 2014). Meta-analyses have shown that emotional intelligence is positively related to mindfulness (Miao et al., 2018b), so training in mindfulness might improve emotional intelligence competencies, and conversely, training in emotional intelligence competencies might also improve mindfulness. Indeed, a qualitative review of the literature has found that training in mindfulness is designed mostly to reduce stress, which suggests that it is useful for mitigating negative emotions (Eby et al., 2019).

\section{The Role of Leader Empathy and Organizational Support in Helping Employees Cope}

In Chapter 3, Amirzadeh and her co-authors address the important issue of social rejection, and they argue that managers should take a leading role in helping employees cope with such rejection. Indeed, empathic and emotionally intelligent leaders are likely to be of considerable value in helping employees cope with the wide variety of negative emotions covered in this book. This perspective is consistent with work on leader empathy. Indeed, Humphrey and his co-authors (see Burch et al., 2016; Humphrey, 2002; Kellett et al., 2006) have argued that empathy is crucial to leadership and helps leaders change their followers' negative emotions into productive positive feelings of confidence, optimism, and enthusiasm.

Supervisors also need support, and Talukder (chapter 9) goes over the importance of family support to supervisors. In a fascinating empirical study, Talukder found that supervisor family support was related to not only the supervisor's job satisfaction and life satisfaction, but also to the supervisor's organizational commitment and job performance.

\section{The Benefits to Organizations of Solving Employee Negative Emotions: Better Performance and Organizational Commitment}

Although we already discussed learning orientation as an individual personality trait or orientation, organizations can also adopt a learning orientation that encourages employees to see 
failure as a learning opportunity and as an inevitable result of innovation efforts. Organizations that take a learning orientation have a sustainable market advantage and increased organizational performance (Baker \& Sinkula, 1999). Thus, transformational leaders should help their employees cope with the negative emotions that come from failure by creating a culture that interprets failure as part of the learning and innovation process (Coad \& Berry, 1998).

Ashkanasy and Härtel (2014) note further that organizations are steeped in emotion that, just as in individuals, can fluctuate from day-to-day. Moreover, consistent with the affect circumplex model (Tellegen et al., 1999), these authors argue that positive and negative emotions can and do frequently co-exist in organizations. Thus, organizational members striving for an important goal may simultaneously experience exhilaration (that a much-anticipated goal is close to attainment) and dread that something will go wrong (and the opportunity will be missed). The key here is to develop a resilient organizational emotional culture (Härtel, 2008) based in positive emotions that can enable organizational members to overcome emotional obstacles and to retain a positive outlook. This theme is taken up in Chapter 1, where Smollan and Singh discuss how "failing" is not the same as "failure" and how employees can employ resilience to overcome obstacles that lead ultimately to success. They cite in particular the work of Moenkemeyer and colleagues (2012), noting that these authors, "have documented how selfefficacy, outcome expectancy, optimism, hope, self-esteem, and risk propensity, built the resilience of team members." A similar message emerges in Chapter 2, where authors Russell and Victoria identify the three distinct emotional coping strategies we discussed earlier and document how resilient "sustainability change agents" can deal with setbacks and help organizations to deal constructively with (apparent) setbacks.

Developing effective emotional labor display rules may be key to creating a positive organizational climate. In chapter 5, Dickason gives a powerful demonstration of this in her 
analysis of emotional labor in hospital settings. She discusses both effective and ineffective uses of emotional labor, and thus provides a useful guide as to how to improve the performance of emotional labor. In chapter 6, Fischbach and Schneider give an insightful analysis of how context influences emotional labor, and they develop a model of emotional labor built around the characteristics of jobs, roles, and levels of professionalism. Thus, like Humphrey et al. (2008), they demonstrate how specific job duties determine the type of emotional labor performed by people at work. An understanding of how these job duties influence the emotions that people feel at work can help organizations lead with the right forms of emotional labor (Humphrey, 2008; Humphrey et al., 2015).

\section{Conclusions}

The chapters in this volume have explored a variety of intense and frustrating negative emotions and emotion arousing events, including failure, social rejection, unethical behavior, burnout, and being the victim and recipient of anger. Although some of these events seem to have no positive benefits, in some cases the events have serendipitous long-term consequences, insofar as they can stimulate learning, personal growth, innovation, and positive change.

Even when there is no upside, there may still be solutions to these vexing negative feelings and workplace problems. Cognitive reappraisal, for example, is a well-established and effective method for coping with negative emotions (cf. Folkman, 2020). When done properly, it can help people reframe their interpretation of events along more productive and useful lines of thinking and feeling.

Emotional intelligence has also emerged as a powerful predictor of a variety of personal and professional outcomes, ranging from well-being, physical and mental health, and overall life satisfaction to more work-specific outcomes such as job satisfaction, organizational commitment, 
and job performance both as followers and as leaders. Fortunately, our emotional intelligence and related emotional competencies are not fixed and predetermined at birth. They can be improved with training; people can learn to be more emotionally competent (see the chapters in Ciarrochi \& Mayer, 2013).

In addition, a related skill, mindfulness, can also be taught and has been shown to help with stress and other negative emotions (see Glomb et al., 2011). Moreover, individual psychological resiliency can be increased, and organizations can also develop programs to help their employees experience resiliency. Organizational support and leader empathy can go a long way towards solving many of the problems discussed in this volume.

Organizations can also develop positive organizational cultures (e.g., see Ashkanasy \& Härtel, 2014) that reduce the occurrence of negative emotions and that promote positive emotions and overall well-being among their employees. There is a benefit to organizations in doing so because a positive organizational culture also increases performance and financial performance.

In sum, the theme of this volume, "Emotions and Negativity" is not all bad. Chapter authors detail a wide-ranging set of means to ameliorate negative emotions in organizational settings. Moreover, as we note in this concluding section, even when there seems to be no upside, help may still be at hand.

\section{References}

Andrei, F., Siegling, A. B., Aloe, A. M., Baldaro, B., \& Petrides, K. V. (2016). The incremental validity of the Trait Emotional Intelligence Questionnaire (TEIQue): A systematic review and meta-analysis. Journal of Personality Assessment, 98, 261-276.

https://doi.org/10.1080/00223891.2015.1084630 
Ashkanasy, N. M., \& Daus, C. S. (2005). Rumors of the death of emotional intelligence in organizational behavior are vastly exaggerated. Journal of Organizational Behavior, 26, 441-452. https://doi.org/10.1002/job.320

Ashkanasy, N. M., \& Härtel, C. E. J. (2014). Positive and negative affective climate and culture: The good, the bad, and the ugly. In B. Schneider \& K. Barbera (Eds.), The Oxford handbook of organizational culture and climate (pp. 136-152). New York: Oxford University Press. https://doi.org/10.1093/oxfordhb/9780199860715.013.0008

Ashkanasy, N. M., \& Humphrey, R. H. (2011). A multi-level view of leadership and emotions: Leading with emotional labor. In A. Bryman, D. Collinson, K. Grint, B. Jackson, \& M. Uhl-Bien (Eds.), Sage handbook of leadership (pp. 365-379). London, UK: Sage Publications.

Ashkanasy, N. M., Humphrey, R. H., \& Huy, Q. N. (2017). Integrating emotions and affect in theories of management. Academy of Management Review, 42, 175-189. https://doi.org/10.5465/amr.2016.0474

Baker, W. E., \& Sinkula, J. M. (1999). The synergistic effect of market orientation and learning orientation on organizational performance. Journal of the Academy of Marketing Science, 27, 411-427. https://doi.org/10.1177/0092070399274002

Bar-On, R. (1997). Bar-On Emotional Quotient Inventory (EQ-i): Technical Manual. Toronto, Canada: Multi-Health Systems.

Bartone, P. T. (2006). Resilience under military operational stress: Can leaders influence hardiness? Military Psychology, 18(Suppl.), S131-S148. https://doi.org/10.1207/s15327876mp1803s_ 10 
Bezuijen, X. M., van Dam, K., van den Berg, P. T., \& Thierry, H. (2010). How leaders stimulate employee learning: A leader-member exchange approach. Journal of Occupational and Organizational Psychology, 83, 673-693. https://doi.org/10.1348/096317909X468099

Boyatzis, R. E. (2011). Managerial and leadership competencies: A behavioral approach to emotional, social and cognitive intelligence. Vision: The Journal of Business Perspective, 15, 91-100. https://doi.org/10.1177/097226291101500202

Brown, K. W., \& Ryan, R. M. (2003). The benefits of being present: mindfulness and its role in psychological well-being. Journal of Personality and Social Psychology, 84, 822. https://doi.org/10.1037/0022-3514.84.4.822

Burch, G. F., Bennett, A. A., Humphrey, R. H., Batchelor, J. H, \& Cairo, A. (2016). Unraveling the complexities of empathy research: A multi-level model of empathy in organizations. In N. M. Ashkanasy, C. E. J. Härtel, \& W. J. Zerbe (Eds.), Research on emotion in organizations (Volume 12, pp. 169-189). Bingley, UK: Emerald Group Publishing. http://dx.doi.org/10.1108/S1746-979120160000012006

Burch, G. F., Humphrey, R. H., \& Batchelor, J. H. (2013). How great leaders use emotional labor: Insights from seven corporate executives. Organizational Dynamics, 42, 119-125. http://dx.doi.org/10.1016/j.orgdyn.2013.03.005

Ciarrochi, J., \& Mayer, J. D. (Eds.). (2013). Applying emotional intelligence: A practitioner's guide. New York: Psychology Press.

Coad, A. F., \& Berry, A. J. (1998). Transformational leadership and learning orientation. Leadership \& Organization Development Journal, 19, 164-172. https://doi.org/10.1108/01437739810210211 
De Pater, I. E., Van Vianen, A. E., Humphrey, R. H., Sleeth, R. G., Hartman, N. S., \& Fischer, A. H. (2009). Individual task choice and the division of challenging tasks between men and women. Group \& Organization Management, 34, 563-589. https://doi.org/10.1177/1059601108331240

Di Fabio, A., \& Saklofske, D. H. (2018). The contributions of personality and emotional intelligence to resiliency. Personality and Individual Differences, 123, 140-144. https://doi.org/10.1016/j.paid.2017.11.012

Dragoni, L. (2005). Understanding the emergence of state goal orientation in organizational work groups: The role of leadership and multilevel climate perceptions. Journal of Applied Psychology, 90, 1084. https://doi.org/10.1037/0021-9010.90.6.1084

Dweck, C. S., \& Leggett, E. L. (1988). A social-cognitive approach to motivation and personality. Psychological Review, 95, 256-273. https://doi.org/10.1037/0033$\underline{295 \times .95 .2 .256}$

Eby, L. T., Allen, T. D., Conley, K. M., Williamson, R. L., Henderson, T. G., \& Mancini, V. S. (2019). Mindfulness-based training interventions for employees: A qualitative review of the literature. Human Resource Management Review, 29, 156-178. $\underline{\text { http://dx.doi.org/10.1016/j.hrmr.2017.03.004 }}$

Elkhorne, J. L. (1967). Edison - the fabulous drone. 73 Magazine, 46, 52-54.

Folkman, S. (2008). The case for positive emotions in the stress process. Anxiety, Stress, \& Coping, 21, 3-14. https://doi.org/10.1080/10615800701740457

Folkman, S. (2020). Stress, appraisal, and coping. In M. D. Gellerman \& R. R. Turner (Eds.), Encyclopedia of behavioral medicine (pp. 2177-2179). New York: Springer. https://doi.org/10.4135/9781412952576.n198 
Folkman, S., \& Moskowitz, J. T. (2007). Positive affect and meaning-focused coping during significant psychological stress. In M. Hewstone, H. A. W. Schut, J. B. F. D. Wit, K. V. D. Bos, \& M. S. Stroebe (Eds.), The scope of social psychology: Theory and Applications (pp. 193-208). New York: Psychology Press. https://doi.org/10.4324/9780203965245

Glomb, T. M., Duffy, M. K., Bono, J. E., \& Yang, T. (2011). Mindfulness at work. In Research in personnel and human resources management (pp. 115-157). Bingley, UK: Emerald Group Publishing. https://doi.org/10.1108/s0742-7301(2011)0000030005

Gross, J. J., \& John, O. P. (2003). Individual differences in two emotion regulation processes: Implications for affect, relationships, and well-being. Journal of Personality and Social Psychology, 85, 348-362. https://doi.org/10.1037/0022-3514.85.2.348

Guo, M., Gan, Y., \& Tong, J. (2013). The role of meaning-focused coping in significant loss. Anxiety, Stress, \& Coping, 26, 87-102. https://doi.org/10.1080/10615806.2011.627507

Härtel, C. E. (2008). How to build a healthy emotional culture and avoid a toxic culture. Research companion to emotion in organizations, In. C. L. Cooper \& N. M. Ashkanasy (Eds.), Research companion to emotion in organizations (pp. 575-588). Cheltenham, UK: Edward Elgar. https://doi.org/10.4337/9781848443778.00049

Henderson, D. (2007). From telegraph to light bulb with Thomas Edison. New York: B\&H Publications.

Hodzic, S., Scharfen, J., Ripoll, P., Holling, H., \& Zenasni, F. (2018). How efficient are emotional intelligence trainings: A meta-analysis. Emotion Review, 10, 138-148. https://doi.org/10.1177\%2F1754073917708613

Humphrey, R. H. (2002). The many faces of emotional leadership. The Leadership Quarterly, 13, 493-504. https://doi.org/10.1016/S1048-9843(02)00140-6 
Humphrey, R. H. (2008). The right way to lead with emotional labor. In Humphrey, R. H. (Ed.), Affect and emotion: New directions in management theory and research (pp. 1-17).

Charlotte, NC: Information Age Publishing.

Humphrey, R. H. (2012). How do leaders use emotional labor? Journal of Organizational Behavior, 33, 740-744. https://doi.org/10.1002/job.1791

Humphrey, R. H. (2013). Effective leadership: Theory, cases, and applications. Thousand Oaks, CA: Sage.

Humphrey, R. H., Ashforth, B. E., \& Diefendorff, J. M. (2015). The bright side of emotional labor. Journal of Organizational Behavior, 36, 749-769. https://doi.org/10.1002/job.2019

Humphrey, R. H., Pollack, J. M., \& Hawver, T. H. (2008). Leading with emotional labor. Journal of Managerial Psychology, 23, 151-168. https://doi.org/10.1108/02683940810850790

Jordan, P. J., \& Troth, A. C. (2002). Emotional intelligence and conflict resolution: Implications for human resource development. Advances in Developing Human Resources, 4, 62-79. https://doi.org/10.1207/s15327043hup1702_4

Jordan, P. J., \& Troth, A. C. (2004). Managing emotions during team problem solving: Emotional intelligence and conflict resolution. Human Performance, 17, 195-218. https://doi.org/10.1177/1523422302004001005

Kellett, J. B., Humphrey, R. H., \& Sleeth, R. G. (2006). Empathy and the emergence of task and relations leaders. The Leadership Quarterly, 17, 146-162. https://doi.org/10.1016/j.leaqua.2005.12.003

Leonard, E. M., Miles, L. E., \& Van der Kar, C. S. (1942). The child at home and school. New York: American Book Company. 
Luthans, F. (2002). The need for and meaning of positive organizational behavior. Journal of Organizational Behavior, 23, 695-706. https://doi.org/10.1002/job.165.

Luthans, F., Vogelgesang, G. R., \& Lester, P. B. (2006). Developing the psychological capital of resiliency. Human Resource Development Review, 5, 25-44. https://doi.org/10.1177/1534484305285335

Martins, A., Ramalho, N., \& Morin, E. (2010). A comprehensive meta-analysis of the relationship between emotional intelligence and health. Personality and Individual Differences, 49, 554-564. https://doi.org/10.1016/j.paid.2010.05.029

Mattingly, V., \& Kraiger, K. (2019). Can emotional intelligence be trained? A meta-analytical investigation. Human Resource Management Review, 29, 140-155. https://doi.org/10.1016/j.hrmr.2018.03.002

Mayer, J. D. (2002). MSCEIT: Mayer-Salovey-Caruso emotional intelligence test. Toronto, Canada: Multi-Health Systems.

Mesmer-Magnus, J., Manapragada, A., Viswesvaran, C., \& Allen, J. W. (2017). Trait mindfulness at work: A meta-analysis of the personal and professional correlates of trait mindfulness. Human Performance, 30, 79-98. https://doi.org/10.1080/08959285.2017.1307842

Miao, C., Humphrey, R. H., \& Qian, S. (2016). Leader emotional intelligence and subordinate job satisfaction: A meta-analysis of main, mediator, and moderator effects. Personality and Individual Differences, 102, 13-24 https://doi.org/10.1016/j.paid.2016.06.056

Miao, C., Humphrey, R. H., \& Qian, S. (2017a). A meta-analysis of emotional intelligence and work attitudes. Journal of Occupational and Organizational Psychology, 90, 177-202. https://doi.org/10.1111/joop.12167 
Miao, C., Humphrey, R. H., \& Qian, S. (2017b). Are the emotionally intelligent good citizens or counterproductive? A meta-analysis of emotional intelligence and its relationships with organizational citizenship behavior and counterproductive work behavior. Personality and Individual Differences, 116, 144-156. https://doi.org/10.1016/j.paid.2017.04.015

Miao, C., Humphrey, R. H., \& Qian, S. (2017c). A meta-analysis of emotional intelligence effects on job satisfaction mediated by job resources, and a test of moderators. Personality and Individual Differences, 116, 281-288. https://doi.org/10.1016/j.paid.2017.04.031

Miao, C., Humphrey, R. H., \& Qian, S. (2018a). A cross-cultural meta-analysis of how leader emotional intelligence influences subordinate task performance and organizational citizenship behavior. Journal of World Business, 53, 463-474. https://doi.org/10.1016/j.jwb.2018.01.003

Miao, C., Humphrey, R. H., \& Qian, S. (2018b). The relation between emotional intelligence and trait mindfulness: A meta-analytic review. Personality and Individual Differences, 135, 101-107. https://doi.org/10.1016/j.paid.2018.06.051

Moenkemeyer, G., Hoegel, M., \& Weiss, M. (2012). Innovator resilience potential: A process perspective of individual resilience as influenced by innovation project termination. Human Relations, 65, 627-655. https://doi.org/10.1177/0018726711431350

Newcombe, M. J., \& Ashkanasy, N. M. (2002). The role of affect and affective congruence in perceptions of leaders: An experimental study. The Leadership Quarterly, 13, 601-614. https://doi.org/10.1016/S1048-9843(02)00146-7

O’Boyle Jr, E. H., Humphrey, R. H., Pollack, J. M., Hawver, T. H., \& Story, P. A. (2011). The relation between emotional intelligence and job performance: A meta-analysis. Journal of Organizational Behavior, 32, 788-818. https://doi.org/10.1002/job.714 
Petrides, K. V., Pérez-González, J. C., \& Furnham, A. (2007). On the criterion and incremental validity of trait emotional intelligence. Cognition and Emotion, 21, 26-55. https://doi.org/10.1080/02699930601038912

Sarrionandia A., \& Mikolajczak, M. (2020). A meta-analysis of the possible behavioural and biological variables linking trait emotional intelligence to health, Health Psychology Review, 14, 220-244. https://doi.org/10.1080/17437199.2019.1641423

Schutte, N. S., \& Malouff, J. M. (2011). Emotional intelligence mediates the relationship between mindfulness and subjective well-being. Personality and Individual Differences, 50, 1116-1119. https://doi.org/10.1016/j.paid.2011.01.037

Schutte, N. S., Malouff, J. M., Thorsteinsson, E. B., Bhullar, N., \& Rooke, S. E. (2007). A metanalytic investigation of the relationship between emotional intelligence and health. Personality and Individual Differences, 42, 921-933. https://doi.org/10.1016/j.paid.2006.09.003

Tellegen, A., Watson, D., \& Clark, L. A. (1999). On the dimensional and hierarchical structure of affect. Psychological Science, 10, 297-303. https://doi.org/10.1111/1467-9280.00157

Troth, A. C., Lawrence, S. A., Jordan, P. J., \& Ashkanasy, N. M. (2018). Interpersonal emotion regulation in the workplace: A conceptual and operational review and future research agenda. International Journal of Management Reviews, 20, 523-543. https://doi.org/10.1111/ijmr.12144

Troth, A. C., Rafferty, A. E., \& Jordan, P. J. (2021). Emotions and wellbeing at work: A multilevel perspective. In T. Wall, C. L. Cooper., \& P. Brough (Eds.), The Sage handbook of organizational wellbeing (pp. 56-71). Thousand Oaks, CA: Sage. https://doi.org/10.4135/9781529757187.n5 
Vernon, P. A., Petrides, K. V., Bratko, D., \& Schermer, J. A. (2008). A behavioral genetic study of trait emotional intelligence. Emotion, 8, 635-642. https://doi.org/10.1037/a0013439

Wright, C. J., \& Schutte, N. S. (2014). The relationship between greater mindfulness and less subjective experience of chronic pain: Mediating functions of pain management selfefficacy and emotional intelligence. Australian Journal of Psychology, 66, 181-186. https://doi.org/10.1111/ajpy.12041 
Table 1. Representative findings from meta-analyses of emotional intelligence effects

Employee emotional intelligence is the best predictor of:

Job Satisfaction — (Miao et al., 2017a, 2017c)

Organizational Commitment- (Miao et al., 2017a)

Turnover Intentions - (Miao et al., 2017a)

Organizational Citizenship Behavior-(Miao et al., 2017b)

Counterproductive Work Behavior- (Miao et al., 2017b)

Employee emotional intelligence is second best predictor (after cognitive ability) of:

Job Performance- (O’Boyle et al., 2011)

Leader emotional intelligence is the best predictor of:

Follower Job Satisfaction (Miao et al., 2016)

Follower task performance (Miao et al., 2018a)

Follower Organizational Citizenship Behavior (Miao et al., 2018a)

Note: All results include controls for cognitive ability and each of the Big Five personality traits. 